\title{
Oriental Herbal as Foliar Nutrients on Lettuce (Lactuca sativa L.) Production
}

\author{
${ }^{1}$ Clint Jay M. Lasco \\ Department of Plant Science, College of Agriculture, \\ Mindanao State University- Main Campus \\ Marawi City, 9700, Lanao del Sur, Philippines
}

\begin{abstract}
The experiment was conducted at the College of Agriculture- Laboratory, Mindanao State UniversityMarawi City. Objective of the study is to determine the effects of Oriental Herbal Nutrients (OHN) on the growth and yield performance of lettuce. Treatments are: $\mathbf{T}_{1}$ (Garlic), $\mathbf{T}_{\mathbf{2}}$ (Ginger), $\mathbf{T}_{3}$ (Black Pepper), $\mathbf{T}_{4}$ (Onion), and $T_{5}$ (Control) with a dilution rate of concoction of 1 tbsp. OHN: 1 liter of water. The experiment was laid out in a Randomized Complete Block Design (RCBD) with three replications. Plant height, number of leaves developed, pest incidence, insect damage rate, weight per plant, and yield per plot were measured. Result showed that the highest treatment mean $\left(6.32 \mathrm{~cm}\right.$.) was recorded in $T_{4}$ and the lowest $\left(4.03 \mathrm{~cm}\right.$.) was in $T_{5}$ which revealed a highly significant effect. The highest treatment mean (5.17) for the number of leaves was found in $\mathbf{T}_{\mathbf{4}}$ and the lowest (3.89) was observed in $T_{5}$. In the case of insect damage rate, the highest treatment mean scale of 1.98 was obtained in $T_{5}$ and the lowest (1.31) was observed in $T_{3}$. In addition, the highest treatment mean (4.91) for pest incidence was observed in $T_{5}$ and the lowest $(2.08)$ was found in $T_{1}$ which showed a highly significant result as well. In addition, the weight per plant revealed the highest treatment mean (49.25) in $T_{4}$ and the lowest (29.41) was observed in $T_{5}$. Study revealed that the highest and lowest yield per plot with 4.15 and 2.57 treatment mean were observed in $\mathbf{T}_{4}$ and $\mathbf{T}_{5}$, respectively. In this experiment, the application of $\mathrm{OHN}$ significantly influences the growth and yield performance of lettuce.
\end{abstract}

Keywords:- Lettuce, Oriental Herbal, Randomized Complete Block Design (RCBD)

\section{INTRODUCTION}

In the Philippine bazaars, lettuce is rarely produced and made available. However, due to its nutritive value and significance to sustain health and development, farmers are now engaging into lettuce production. In addition, the major role of agriculture at present is to sustain safe foods to support the demand of the increasing population. Health issues and environmental sustainability emerged as a major problem as well. This becomes a challenge to farmers and producers to shift from chemical-based farming into traditional and natural-based type of agriculture. Therefore, it is essential to develop a technology in agriculture ensuring safe foods and determine apt fertilizers to improve the commodity's production and quality.

\author{
${ }^{2}$ Abdani D. Bandera \\ Assistant Professor I, College of Agriculture, Mindanao \\ State University- Buug Campus \\ Buug, Zamboanga Sibugay, 7009, Philippines
}

Lettuce (Lactuca sativa L.) is a member of the family Asteraceae (Compositae), a successful and diverse group of plants with a global distribution [6]. Cultivated lettuce is grouped into seven different types: Cos (Romaine), Cutting (Leaf), Stalk (Asparagus), Butterhead, Crisphead (Iceberg or Cabbage), Latin, and Oilseed [10], [4]. [5] identified that Lettuce is an economically important salad vegetable next to tomato. It is a good source of high dietary fiber (1.1 $\mathrm{g} / 100 \mathrm{~g}, \mathrm{FW})$, vitamin A (166 lg/ $100 \mathrm{~g}$, FW), folate or vitamin B9 (73 lg/100 g, FW), vitamin C (4 mg/100 g, $\mathrm{FW})$, vitamin $\mathrm{K}(24 \mathrm{lg} / 100 \mathrm{~g})$, and phenolic compounds. Since lettuce is very low in calories $(10 \mathrm{kcal}[60 \mathrm{~kJ}] / 100 \mathrm{~g}$, $\mathrm{FW}$ ), it is often prescribed for weight loss programs [9]. Consumption of lettuce is reported to improve health benefits such as its higher dietary fiber content that aids in digestion. The higher $b$-carotene and lutein content in lettuce is associated with reducing risk of cancers, cataracts and heart disease and stroke [12]. In addition, phenolic compounds in plants are responsible for antioxidant scavenging properties. Carotenoids possess antioxidant capacity and vitamin $\mathrm{C}$, the water soluble antioxidant, also shows antioxidant properties [7]. Colorful lettuce types have increased in recent years and darker lettuce types (romaine, green leaf and red leaf) were reported to be better sources for vitamin A, niacin, riboflavin, thiamine, $\mathrm{Ca}, \mathrm{Fe}$, $\mathrm{K}, \mathrm{Mn}, \mathrm{Se}$ and $b$-carotene [1]. Different types of lettuce with various colors and shapes are packaged for fresh cut salad mixes [8]. However, the phytochemical content and composition can vary among different varieties and it is important to choose certain type of varieties that are rich in phytochemicals.

[2] identified that Lettuce is preferably grown in hydroponic system, and the growth rate of a hydroponic plant is faster and the yield is higher than a soil grown plant produced under the same conditions. Also, the hydroponic system uses less water due to the constant reuse of nutrient solution and also reduces the risk of soil borne diseases [2]. Phytochemical contents in fresh produce can be improved when osmotic or salt stress is created with a high nutrient solution electrical conductivity (EC) in the root zone in a hydroponic system [3].

Lettuce is now found an important produce. Farmers and farm owners begin including the commodity into the main enterprise of their establised farming system. However, the application of inorganic fertilizers i.e. Urea (46-0-0), Muriate of Potash (0-0-60), Complete Fertilizers (14-14-14), and Ammonium Sulfate (21-0-0) to boost the production still exist. Thus, This study introduces the use of 
Oriental Herbal Nutients mixed with inorganic fertilizers to produce foods free from toxic phytochemicals.

\section{MATERIALS AND METHODS}

The variety used for this study was Grande Iceberg Lettuce. It produces large heads with attractive interior. It grows best in silt loams and lightly-textured soils which provides better drainage during cold weather and warm up more readily. [11] pointed out that Lettuce is a cool-season crop with distinct temperature requirement. The importance of this variety to this study is its suitability to the experimental area's topography and temperature since its optimal growing temperature is $23{ }^{\circ} \mathrm{C}$ during the day and it can be grown both in lowlands and highlands. Before nursery, seedling trays were filled with soil media then sprinkled with water, enough to moisten the soil.

The experiment was laid out in Randomized Complete Block Design (RCBD) with five treatments $\mathrm{T}_{1}$ (Garlic), $\mathrm{T}_{2}$ (Ginger), $\mathrm{T}_{3}$ (Black pepper), $\mathrm{T}_{4}$ (Onion), $\mathrm{T}_{5}$ (Control) replicated three times. The independent variable in this study was the plants with $\mathrm{OHN}$ concoctions. However, dependent variables measured and observed were the growth and yield performance of Lettuce, pest incidence, insect damage rate and Return on Investment (ROI). The data were analyzed using the Analysis of Variance (ANOVA) of the Randomized Complete Block Design (RCBD) to test the difference between two or more means. In this study, Tukeys' Honest Significant Difference (HSD) Test were also used to interpret the data.

\begin{tabular}{|c|c|}
\hline Treatments & Description \\
\hline $\mathbf{T}_{\mathbf{1}}$ & $\begin{array}{c}\text { = Garlic with the dilution rate of 1 tbsp. in } \\
1000 \text { ml. of water }\end{array}$ \\
\hline $\mathbf{T}_{\mathbf{2}}$ & $\begin{array}{c}\text { = Ginger with the dilution rate of 1 tbsp. } \\
\text { in 1000 ml. of water }\end{array}$ \\
\hline $\mathbf{T}_{\mathbf{3}}$ & $\begin{array}{c}\text { = Black pepper with the dilution rate of 1 } \\
\text { tbsp. in 1000 ml. of water }\end{array}$ \\
\hline $\mathbf{T}_{\mathbf{4}}$ & = Control with no OHN applied \\
\hline $\mathbf{T}_{\mathbf{5}}$ & 1000 ml. of water \\
\hline
\end{tabular}

Treatments $(T)$

The area was ploughed using tractor with rotating disc plow. Primary and secondary tillage operation were done. After the tillage operation, the area was cleared and cultivated using hand trowel to ensure good root penetration. Harrowing and furrowing were both done in the experimental area. The seeds were sown into the prepared seed box with the ratio of 1:1 fine soil and vermicast as growing media. After 14 days, transplanting operation was done by putting one seedling per hill at a distance of $25 \mathrm{~cm}$ between hills and $30 \mathrm{~cm}$ between rows. Transplanting was done in the late afternoon to reduce stress. Seedlings were transplanted into the field. Irrigation was done to ensure the seedlings were filled with enough moisture content to develop.
Complete fertilizer (14-14-14) was applied during the early stage of the plant. Urea (46-0-0) was applied on its reproductive stage (side dressing). Botanical herb treatments such as Garlic (A. sativum), Ginger (Zingiber officinale), Black Pepper (Piper nigrum L.), and Onion (Allium cepa L.) were chopped and crushed separately. Each freshly chopped herbs weighted $1 \mathrm{~kg}$ were put into its individual aseptic jars. Every individual jar, an equally amount of muscovado weighted $1 \mathrm{~kg}$ were added. Every jar was sealed and covered with muslin or a paper towel and secured with a rubber band. It was fermented for seven days out of direct sunlight.

After 7 days of fermentation, treatments were filled with native tuba vinegar. In a room, it was stirred clockwise with a wooden spoon. Every morning, preferably replace the jar's cover to avoid contamination. After 14 days, the individual prepared treatment of botanical herbs was strained. For the concoction, mix the following - 1 tbsp. of OHN: 1 Liter of water.

The experiment was laid out in a Randomized Complete Block Design (RCBD) with three replications. There were 12 treatment combinations such as $R_{l} T_{1}, R_{l} T_{2}$, $R_{l} T_{3}, R_{1} T_{4}, R_{1} T_{5}, R_{2} T_{1}, R_{2} T_{2}, R_{2} T_{3}, R_{2} T_{4}, R_{2} T_{5}, R_{3} T_{1}, R_{3} T_{2}$, $R_{3} T_{3}, R_{3} T_{4}, R_{3} T_{5}$. There were 15 unit plots and the size of each unit plot was $2.75 \mathrm{~m} \times 1.50 \mathrm{~m}$. Oriental Herbal Nutrient was applied throughout the early vegetative stage and reproductive stage of the crop. The solution ratio was 1 tbsp.: $1000 \mathrm{ml}$. in water. The ratio can be changed depending on the weather or the condition of the plant.

Without ample rain, seedling must be supplied with water regularly so that plants can withstand adverse environmental condition. Irrigation schedule was done every morning and late afternoon with the use of sprinkler. In addition, hand weeding was done to avoid nutrient and water competition and to evade pest infestation. Application of oriental herbal nutrients concoction was used to control pest and diseases. This was done by spraying into the leaves of the plant. This served as pest infestation control and disease infection resistant.

Lastly, After 40 days of transplanting, plants were harvested. This was done in the late afternoon by carefully cutting the basal whorl of the plant with the aid of harvesting tools such as knife.

In this study, the data gathered are plant height $(\mathrm{cm})$, number of leaves, weight of plants (gram), and yield per plant (gram). Height/plant $(\mathrm{cm})$ was taken by measuring (20) representative sample plants per treatment per replication. The measurement was based from the basal whorl to the highest leaf attached to the plant. Data collection will be done every week. Number of leaves/plant was done by counting the total number of leaves of the (20) sample plants per treatment per replication weekly. Weight/plant (grams) was determined by weighing the (20) random sample plants in a treatment during harvest time. Yield/Plot (tons/ha) was done by weighing all the harvested plants per plot and computed using the formula below: 


$$
\begin{gathered}
\text { Yield }=\frac{\text { Plot Yield }(\mathrm{g})}{\text { Plot Area }(\mathrm{m} 2)} \times \frac{1 \mathrm{~kg}}{1000 \mathrm{~g}} \times \frac{1 \mathrm{Ton}}{1000 \mathrm{Kg}} \\
\times \frac{10,000 \mathrm{~m} 2}{1 \mathrm{ha}} \times 100
\end{gathered}
$$

\section{RESULTS AND DISCUSSION}

\section{A. Plant Height $(\mathrm{cm})$}

Figure 1 shows the mean data chart on the plant height of Lettuce from 7 to 28 DAT. It indicates that at all growth stages, the tallest plant $(4.5 \mathrm{~cm}, 6.18 \mathrm{~cm}, 7.16 \mathrm{~cm}, 7.46 \mathrm{~cm}$ at 7, 14, 21, 28 DAT, respectively) was recorded from $\mathrm{T}_{4}$ (Onion). This was followed by $\mathrm{T}_{2}$ (Ginger), $\mathrm{T}_{3}$ (Black Pepper), $\mathrm{T}_{1}$ (Garlic) and the shortest plant $(3.07 \mathrm{~cm}, 3.37$ $\mathrm{cm}, 4.63 \mathrm{~cm}, 5.05 \mathrm{~cm}$ at 7, 14, 21, 28 DAT, respectively) was observed from $\mathrm{T}_{5}$ (Control). The analysis of variance (ANOVA) on the Plant height of Lettuce (Lactuca sativa L.) as affected by Oriental Herbal Nutrients showed a highly significant result (Appendix Table 1).
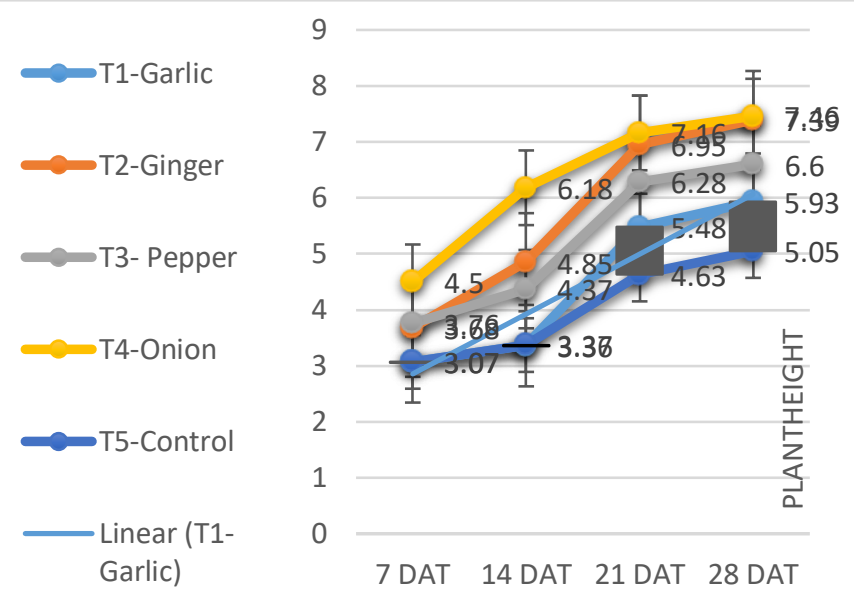

Fig 1:- Mean data chart on the Plant height of Lettuce (cm.) (Lactuca sativa L.) from 7 to 28 DAT as affected by Oriental Herbal Nutrients

\section{B. Number of Leaves}

Figure 2 reveals the mean data chart on the number of leaves of lettuce from 7 to 28 DAT. Result shows that at all growth stages as to the number of leaves, the maximum number of leaves $(3.05,4.7,5.48,7.46$ at $7,14,21,28$ DAT respectively) was recorded from $\mathrm{T}_{4}$ (Onion). This was followed by $\mathrm{T}_{2}$ (Ginger), $\mathrm{T}_{3}$ (Black Pepper), $\mathrm{T}_{1}$ (Garlic) and the minimum number of leaves $(2.78,3.5,4.23,5.05$ at 7 , 14, 21, 28 DAT respectively) was observed from $\mathrm{T}_{5}$ (Control). The analysis of variance (ANOVA) on the number of leaves of lettuce (Lactuca sativa L.) as influenced by Oriental Herbal Nutrients revealed a highly significant result (Appendix Table 2).
ISSN No:-2456-2165
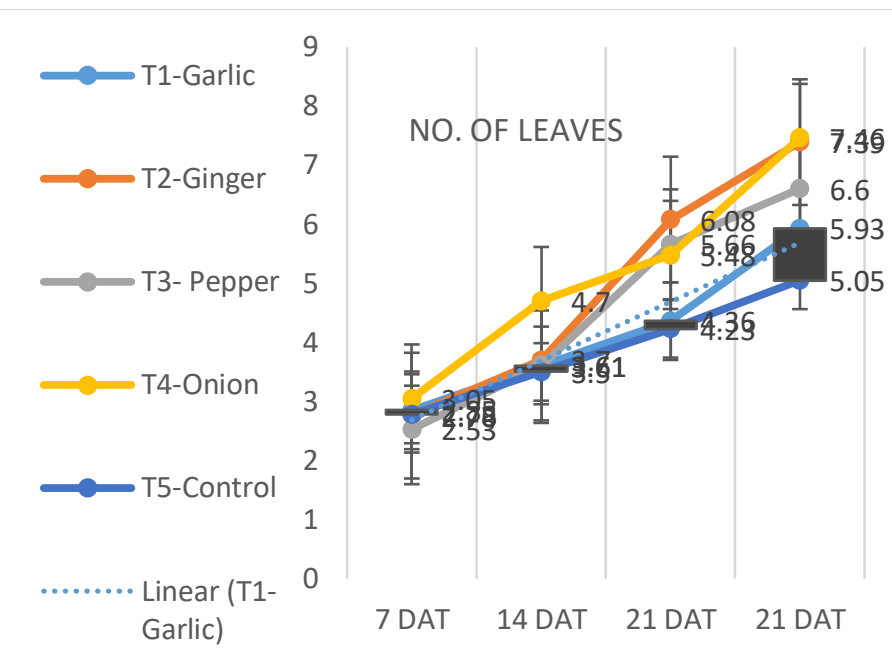

Fig 2:- Mean data chart on the No. of Leaves of Lettuce (Lactuca sativa L.) from 7 to 28 DAT as affected by Oriental Herbal Nutrients

\section{Insect Damage Rate}

Figure 3 shows the mean data chart on the insect damage rating of lettuce from 7 DAT to 28 DAT. It indicates that at all growth stages as to the insect damage rate, the highest treatment $(1.75,2.06,2.6,1.53$ at $7,14,21$, 28 DAT respectively) was recorded from $\mathrm{T}_{5}$ (control). This was followed by $\mathrm{T}_{4}$ (Onion), $\mathrm{T}_{2}$ (Ginger), $\mathrm{T}_{1}$ (Garlic), and the lowest treatment $(1.23,1.28,1.48,1.28$ at $7,14,21,28$ DAT respectively) was observed from $\mathrm{T}_{3}$ (Black Pepper). The analysis of variance (ANOVA) on the Insect Damage Rating of Lettuce (Lactuca sativa L) from 7 to 28 DAT as affected by Oriental Herbal Nutrients showed a highly significant result (Appendix Table 3).

\section{INSECT DAMAGE RATING}

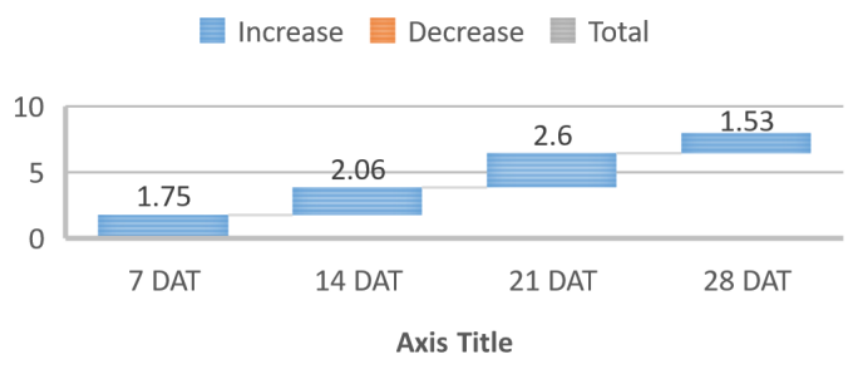

Fig 3:- Mean data chart on the Insect damage rating of Lettuce (Lactuca sativa L.) from 7 to 28 DAT as affected by Oriental Herbal Nutrients 


\section{Pest Incidence}

Figure 4 revealed the mean data on the pest incidence of lettuce from 7 to 28 DAT. It showed that at all growth stages as to the pest incidence, the highest treatment $(5$, $6.33,4.33,4$ at $7,14,21,28$ DAT respectively) was recorded from $\mathrm{T}_{5}$ (Control). This was followed by $\mathrm{T}_{4}$ (Onion), $\mathrm{T}_{2}$ (Ginger), $\mathrm{T}_{3}$ (Black Pepper), and the lowest treatment $(2,2.33,2.66,1.33$ at $7,14,21,28$ DAT respectively) was observed in $\mathrm{T}_{1}$ (Garlic). The analysis of variance (ANOVA) on the Insect Damage Rating of Lettuce (Lactuca sativa L) from 7 to 28 DAT as affected by Oriental Herbal Nutrients showed a highly significant result (Appendix Table 4).

\section{PEST INCIDENCE}

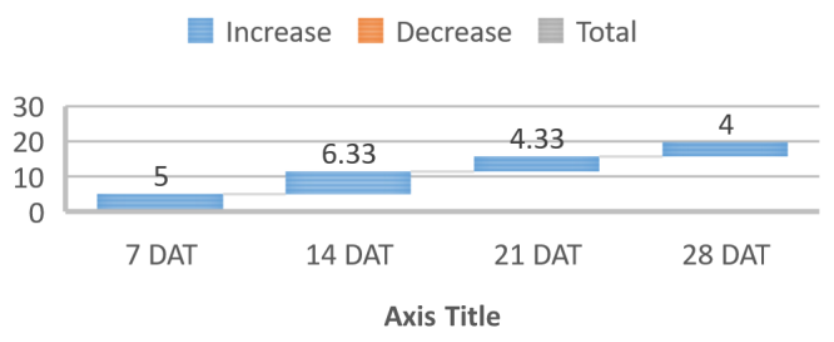

Fig 4:- Mean data chart on the Pest incidence of Lettuce

(Lactuca sativa L.) from 7 to 28 DAT as affected by Oriental Herbal Nutrients

\section{E. weight per plant $(g)$}

Figure 5 shows the mean data of weight per plant of lettuce after harvesting. Result indicates that the highest treatment mean of $49.25 \mathrm{~g}$. was recorded in $\mathrm{T}_{4}$ (Onion), followed by $\mathrm{T}_{2}$ (Ginger), $\mathrm{T}_{3}$ (Pepper), $\mathrm{T}_{1}$ (Garlic), and the lowest treatment mean was obtained in $\mathrm{T}_{5}(\mathrm{Control})$ with a mean of $29.41 \mathrm{~g}$. The analysis of variance (ANOVA) on the Weight per Plant of Lettuce (Lactuca sativa L.) after harvesting as affected by Oriental Herbal Nutrients showed a highly significant result (Appendix Table 5).

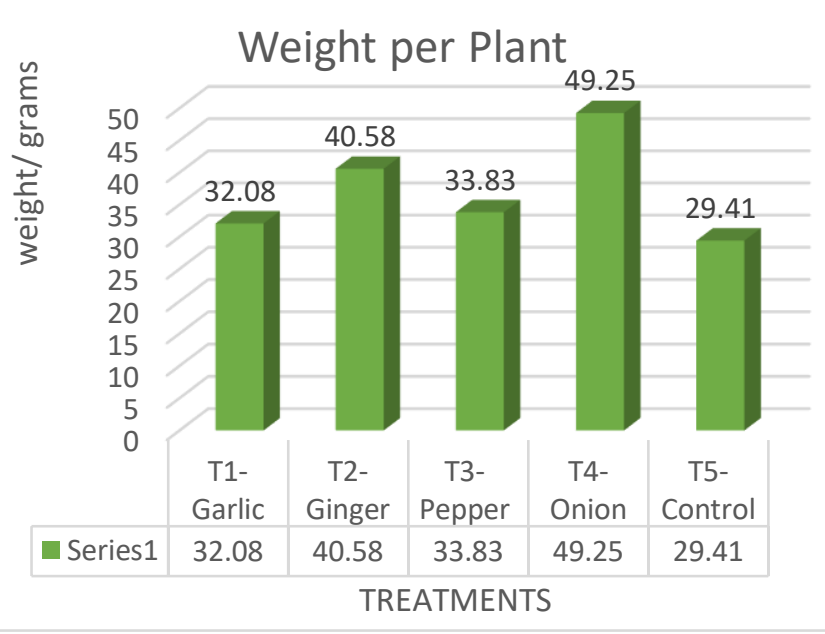

Fig 5:- Mean data chart on the weight per plant (g) of Lettuce (Lactuca sativa L.) after harvesting as affected by Oriental Herbal Nutrients

\section{F. Yield/ Plot}

Figure 6 shows the mean data on the yield per plot of lettuce after harvesting. It indicates that the highest treatment mean was obtained in $\mathrm{T}_{4}$ (Onion) with a mean of $4.15 \mathrm{~kg}$., followed by $\mathrm{T}_{2}$ (Ginger) with a mean of $3.75 \mathrm{~kg}$., followed by $\mathrm{T}_{3}$ (Pepper) with a mean of $3.42 \mathrm{~kg}$., follwed by $\mathrm{T}_{1}$ (Garlic) with a mean of $3.19 \mathrm{~kg}$. The lowest treatment mean was obtained in $\mathrm{T}_{5}$ (Control) with a mean of $2.57 \mathrm{~kg}$. The analysis of variance (ANOVA) on the yield per plot of lettuce (Lactuca sativa L.) after harvesting as affected by Oriental Herbal Nutrients showed a highly significant result (Appendix Table 5).

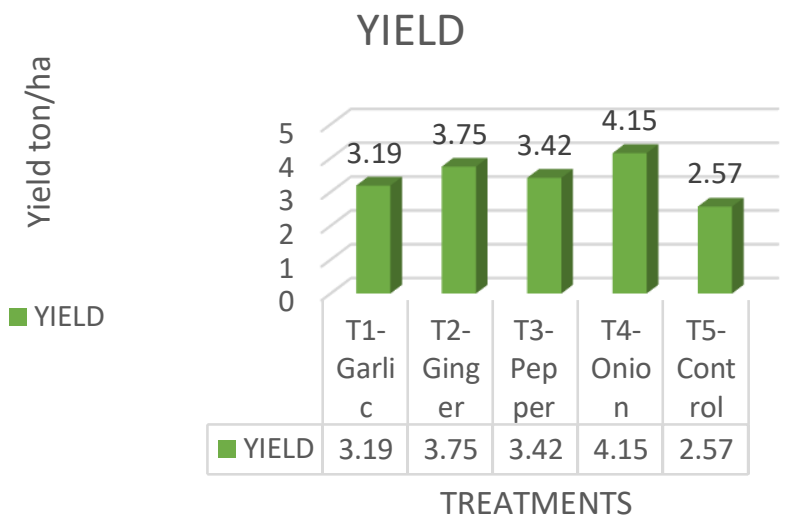

Fig 6:- Chart on the mean data on the mean data on the Yield per plot of Lettuce (Lactuca sativa L.) after havesting as affected by Oriental Herbal Nutrients

\section{CONCLUSION}

The response of the plant as affected by oriental herbal nutrient has significant effect on the growth and yield performance of lettuce. The findings showed that $\mathrm{T}_{4}$ and $T_{2}$ significantly affect the plant height and number of leaves. However, $\mathrm{T}_{4}$ is not effective in controlling insect pest occurrence and insect damage rate. In controlling pest infestation, it was observed that among the treatments, the most effective are $T_{3}$ and $T_{1}$. These treatments have significant effect on the insect pest. Result of the study showed that the overall insect damage rate of the plant falls upon the scale of 2 which has less than $24 \%$ damage of the plant and is deemed stable.

Moreover, the application of Oriental Herbal Nutrient significantly influences the growth and yield performance of lettuce. It has a significant effect on the growth of the plant and number of leaves. The pest incidence of lettuce is higher at early and vegetative stage of the plant since the plant is much succulent and also due to the environmental factors. However, with apt application of $\mathrm{OHN}$, generally, the insect damage rate of the study fell under the scale 2 which means that the damage is less than $24 \%$ of the plants. This showed that the application of Oriental Herbal Nutrients has significant effect on the lettuce that lessens both pest incidence and insect damage rating on the plant. For the Return on Investments (ROI), the cost of production has gain back and profited around $P 915$. 


\section{RECOMMENDATIONS}

The following are recommended:

For the growth and development of lettuce, it was found that $\left(\mathrm{T}_{4}\right)$-Onion and $\mathrm{T}_{2^{-}}$- Ginger is effective in keeping the plant vigorous. In terms of controlling pest and diseases, it was observed that $\mathrm{T}_{3}$-Pepper and $\mathrm{T}_{1}$-Garlic are effective on dealing insect pest incidence.

Further studies are also recommended to verify the result.

\section{APPENDICES}

\begin{tabular}{|c|c|c|c|c|c|c|}
\hline Source of Variation & $\begin{array}{c}\text { Degree of } \\
\text { Freedom }\end{array}$ & Sum of Squares & Mean Square & \multicolumn{2}{|c|}{ Computed F } & \multicolumn{2}{|c|}{} \\
\cline { 3 - 7 } & & & & $5 \%$ & \\
\hline Replication & 3 & 27.8227 & 9.2742 & & 3.26 & 5.41 \\
\hline Treatment & 4 & 13.7738 & 3.4434 & $0.01 * *$ & \\
\hline Error & 12 & 1.7136 & 0.1428 & & \\
\hline Tota & 19 & 43.3100 & & & \\
\hline
\end{tabular}

$\mathrm{cv}=7.33 \%$

$* *$ = highly significant

Table 1:- Analysis of Variance (ANOVA) mean data on the Plant Height of Lettuce (Lactuca sativa L.) at 28 DAT as affected by Oriental Herbal Nutrients

\begin{tabular}{|c|c|c|c|c|c|c|}
\hline \multirow[t]{2}{*}{ Source of Variation } & \multirow{2}{*}{$\begin{array}{l}\text { Degree of } \\
\text { Freedom }\end{array}$} & \multirow{2}{*}{$\begin{array}{l}\text { Sum of } \\
\text { Squares }\end{array}$} & \multirow[t]{2}{*}{ Mean Square } & \multirow[t]{2}{*}{ Computed F } & \multicolumn{2}{|c|}{$\underline{\text { Tabular F }}$} \\
\hline & & & & & $5 \%$ & $1 \%$ \\
\hline Replication & 3 & 38.6608 & 12.8869 & & & \\
\hline Treatment & 4 & 4.5708 & 1.1427 & $2.68 *$ & 3.26 & 5.41 \\
\hline Error & 12 & 3.4020 & 0.2835 & & & \\
\hline Tota & 19 & 46.6337 & & & & \\
\hline
\end{tabular}

$\mathrm{cv}=7.33 \%$

* = significant

Table 2:- Analysis of Variance (ANOVA) mean data on the No. of Leaves of Lettuce (Lactuca sativa L.) as affected by Oriental Herbal Nutrients

\begin{tabular}{|c|c|c|c|c|c|c|}
\hline \multirow[t]{2}{*}{ Source of Variation } & \multirow{2}{*}{$\begin{array}{l}\text { Degree of } \\
\text { Freedom }\end{array}$} & \multirow[t]{2}{*}{ Sum of Squares } & \multirow[t]{2}{*}{ Mean Square } & \multirow[t]{2}{*}{ Computed F } & \multicolumn{2}{|c|}{$\underline{\text { Tabular F }}$} \\
\hline & & & & & $5 \%$ & $1 \%$ \\
\hline Replication & 2 & 0.8844 & 0.2948 & & & \\
\hline Treatment & 4 & 1.2372 & 0.3093 & $0.98^{* *}$ & 3.84 & 7.01 \\
\hline Error & 8 & 0.6825 & 0.0569 & & & \\
\hline Tota & 14 & 2.8041 & & & & \\
\hline
\end{tabular}

$\mathrm{cv}=15.15 \%$

$* *$ = highly significant

Table 3:- Analysis of Variance (ANOVA) mean data on Insect damage rate of Lettuce (Lactuca sativa L.) at 28 DAT as affected by Oriental Herbal Nutrients

\begin{tabular}{|c|c|c|c|c|c|c|}
\hline Source of Variation & $\begin{array}{c}\text { Degree of } \\
\text { Freedom }\end{array}$ & $\begin{array}{c}\text { Sum of } \\
\text { Squares }\end{array}$ & Mean Square & \multicolumn{2}{|c|}{ Computed F } & \multicolumn{2}{|c|}{ Tabular F } \\
\cline { 3 - 7 } & & & & & & \\
\hline Replication & 3 & 3.0778 & 1.0259 & & 3.83 & 17.67 \\
\hline Treatment & 4 & 24.8030 & 6.2007 & $0.11 * *$ & \\
\hline Error & 12 & 7.8819 & 0.6568 & & & \\
\hline Tota & 19 & 35.7627 & & & & \\
\hline
\end{tabular}

$\mathrm{cv}=26.33 \%$

$* *$ = highly significant

Table 4:- Analysis of Variance (ANOVA) mean data on the Pest Incidence of Lettuce (Lactuca sativa L.) at 28 DAT as affected by Oriental Herbal Nutrients 
ISSN No:-2456-2165

\begin{tabular}{|c|c|c|c|c|c|c|}
\hline Source of Variation & $\begin{array}{l}\text { Degree of } \\
\text { Freedom }\end{array}$ & Sum of Squares & Mean Square & \multicolumn{2}{|c|}{ Computed F } & \multicolumn{2}{|c|}{ Tabular F } & $\mathbf{5 \%}$ & $\mathbf{1 \%}$ \\
\hline Replication & 2 & 13.6333 & 6.8167 & & \\
\hline Treatment & 4 & 763.8167 & 190.9542 & $0.07 * *$ & $\mathbf{0 . 5 7}$ & 15.99 \\
\hline Error & 8 & 95.5333 & 11.9417 & & \\
\hline Tota & $\mathbf{1 4}$ & $\mathbf{8 7 2 . 9 8 3 3}$ & & & & \\
\hline
\end{tabular}

$\mathrm{cv}=9.33 \%$

** = highly significant

Table 5:- Analysis of Variance (ANOVA) of Weight/plant (g) Lettuce (Lactuca sativa L.) as affected by Oriental Herbal Nutrients

\section{REFERENCES}

[1]. Bunning, M.L., Kendall, P.A., Stone, M.B., Stonaker, F.H. and Stushnoff, C. (2010). Effects of seasonal variation on sensory properties and total phenolic content of 5 lettuce cultivars. J. Food Sci. 75, 156161.

[2]. Cornish, P.S. (1992). Use of high electrical conductivity of nutrient solution to improve the quality of salad tomatoes grown in hydroponic culture. Aust. J. Exp. Agric. 32, 513-520.

[3]. De Pascale, S., Maggio, A., Fogliano, V., Ambrosino, P. And Ritieni, A. (2001). Irrigation with saline water improves carotenoids content and antioxidant activity of tomato. J. Hort. Sci. Biotechnol. 76, 447-453.

[4]. DeVries, IM (1997). Origin and domestication of Lactuca sativa L. Genet Resour CropEvol 44:165-174

[5]. FAOSTAT. (2012). FAOSTAT Database for Crops [Online], Food and Agricultural Organization of the United Nations (FAO), Rome, Italy. http://faostat.fao.org/site/567/DesktopDefault (accessed August 30, 2012).

[6]. Funk VA, Bayer RJ, Keeley S, Chan R, Watson L, Gemeinholzer B, Schilling E, Panero JL, Baldwin BG, Garcia-Jacas N, Susanna A, Jansen RK (2005) Everywhere but Antaractica: using a super treeto understand the diversity and distribution of the Compositae. Biol Skr55:343-374

[7]. Lopez, A., Javier, G., Fenoll, J., Hell In, P. And Flores, P. (2014). Chemical composition and antioxidant capacity of lettuce: Comparative study of regular-sized (Romaine) and baby-sized (Little Gem and Mini Romaine) types. J. Food Comp. Anal. 33, $39-48$.

[8]. Martinez-Sanchez, A., Luna, M.C., Selma, M.V., Tudela, J.A., Abad, J. and GIL, M.I. (2012). Baby-leaf and multi-leaf of green and red lettuces are suitable raw materials for the fresh-cut industry. Postharvest Biol. Technol. 63, 1-10.

[9]. Niederwieser, J.G. (2001). Guide to Hydroponic Vegetable Production, 2nd Ed., p. 140, Agricultural Research Council, Roodeplaat Vegetable and Ornamental Plant Institute, Pretoria, South Africa.

[10]. Tehrane P (1995) International Code of Nomenclature for Cultivated plants in 1995. RegnumVegetable 133

[11]. Turini, T. (2009). Iceberg lettuce production in California. California: University of California Agriculture and Natural Resources Publication 7215.
[12]. USDA. (2004). U.S. Department of Agriculture, Agricultural Research Service, National nutrient data base for standard Reference, Release 17. http://www.nal.usda.gov/fnic/foodcomp/ Data/SR17/sr17.html (accessed March 27, 2005). 